2020, Volume 14, International Conference Innovative Business Management \& Global Entrepreneurship (IBMAGE 2020), pages: 60-69 |

https://doi.org/10.18662/lumproc/ibmage2020/05

\section{Innovation Alliances in The Context of Quadruple Helix Entrepreneurial Ecosystem}

\section{Liviu CIUCAN-RUSU1, Mihai TIMUS2*}

1 "George Emil Palade" University of Medicine, Pharmacy, Science and Technology, Targu-Mures, liviu.ciucan@umfst.ro

2 "George Emil Palade" University of Medicine, Pharmacy, Science and Technology, Targu-Mures, mihai.timus@,u2b.umfst.ro

* Corresponding Author
Abstract: In nowadays economic environment the collaboration between actor of quadruple helix (academia, public authorities, businesses and support organizations) is crucial. First, because universities are sources of fresh ideas and competences which lead the innovation and second, businesses can offer the pragmatic approach of using these, while public polices struggle to ensure the sustainability of local economic development. We assume that needs of academia and businesses meets at some point. The challenge in this case is to identify these needs and put together the value which can bring each of the parts. Our study aims at identifying the needs of all stakeholders and promote collaboration between them in the context of University as an innovation hub. A survey was conducted during the first quarter of 2020 and data was collected from target group Centre Region of Romania. By the data collected we intend to ensure a better understanding of needs and develop roadmaps of building an entrepreneurial partnership. These actions will support the development process of the university as a local innovation hub. The main aims of the survey were followed: testing the topics of interest on which stakeholders can and intend to collaborate, what are the types of collaboration and if exist the understanding of advantages of collaboration between academia and local businesses and public institutions. The most popular topics of collaboration are: Business, ICT and Finance and Banking. The most popular types of collaborations are common projects for funding competitions followed by common research and development projects in mixed teams and common events, workshops and conferences.

Keywords: innovation alliances, higher education institutions, entrepreneurship, regional development.

How to cite: Ciucan-Rusu, B., \& Timus, M. (2020).

Innovation Alliances in The Context of Quadruple Helix Entrepreneurial Ecosystem. In M. W. Staniewski, V. Vasile, \& A. Grigorescu (vol. ed.), Lumen Proceedings: Vol. 14. International Conference Innovative Business Management \& Global Entrepreneurship (IBMAGE 2020) (pp. 60-69). Iasi, Romania: LUMEN Publishing House.

https://doi.org/10.18662/lumproc/ibmage2020/05 


\section{Introduction}

In the context of contemporary economy, it is getting clearer that the collaboration and knowledge exchange approach is one of the pillars of innovation and regional economic sustainability. Moreover, each university must take on the role of catalyst for the development of the area of interest.

Universities must address the specific stakeholders needs to contribute to a consolidation of regional innovation and entrepreneurship hubs. At this moment, the capitalization of the innovation through spin-offs and partnerships is rather reduced in our region, therefore, a program for supporting interdisciplinary collaboration is needed. Another important pillar for innovation alliances development is legal regulation regarding public and private partnerships. As we know, public authorities try to reduce the legal requirements for this kind of collaborations and to initiate different strategies for stakeholders' stimulations.

Under these circumstances, universities' initiatives and friendly regulations could boost the development of innovation alliances in the context of quadruple helix entrepreneurial ecosystem. We hope that next pages of this study will clarify if there exist interest in taking a part of such an innovation alliance and what are the main topics and fields of collaboration from non-academic actors' perspective.

\section{Problem Statement}

Universities and research centers are, or at least, should be the most important drivers of the regional and national innovation ecosystem in any country [3]. In this case, universities are very welcome in different partnerships where they can bring the knowledge and problem solving experience. The key task is to create a friendly environment for collaboration which can boost the innovation process. A quadruple helix model is very useful in this case. The most important aspect of the quadruple helix is knowledge, circulating between different subsystems of society and thus influencing innovation and knowledge creation [1]. The linkage between academic institutions and public administration or private industries is not clear at this moment, but is getting more popular and businesses are more open now to collaborate with universities and research centers to gain their competitive advantage[6].

Many other authors affirm that the important and key role that universities play is creating new knowledge at a regional level that can be exploited through technology transfer mechanisms and commercialized by firms or entrepreneurs in the region[2]. To support this process, 
stakeholders should reach agreement about quadruple helix approach collaboration. In other words, the most important element of the quadruple helix is knowledge, circulating between different subsystems of society and thus influencing innovation and knowledge creation [4]. The main task of stakeholders in this case is to build and maintain the structure of quadruple helix entrepreneurial ecosystem. To achieve this, actors involved in partnership have to be high on both entrepreneurship and alliance orientations [5].

\section{Research Questions/Aims of the research}

This research paper aims at promoting the entrepreneurial partnerships through quadruple helix approach and identify the most relevant way to stimulate this process. The main questions of this study are as follows:

- What are the topics of interest for collaboration from nonacademic members 'perspective?

- What are the types of collaboration preferred by stakeholders?

- If from non-academic perspective exist an understanding of advantages which come with innovation alliances partnership?

- What is the interest of responders involvement in innovation alliances partnerships?

This study is a start point for further research on needs and initiatives identification of non-academic stakeholders involved quadruple helix partnerships.

\section{Research Methods}

An online survey was conducted during the first quarter of 2020 and data was collected from target group of Centre Region of Romania.

The subjects of the survey are 42 representatives of businesses and public authorities' environment. The online survey was sent to 50 businesses and public authorities from Centre Region of Romania. This research represents a descriptive analysis of data collected from respondents. Figures and data analysis were done by using Microsoft Power Business Intelligence application. To ensure that respondents understood the terminologies and objectives of the survey, research team develop an introduction with basic explanation of the scope and meaning of the questions. 


\section{Findings}

As we discussed above, the quadruple helix collaboration approach is crucial for regional economic development. In order to achieve the performance in this area we need mind openness of people involved, policies for supporting their activities, friendly organizational environment and resources for implementation of ideas.

In this section we will discuss the data collected and the main finding of the study. At the end of this phase we will deliver several recommendations on how to build a sustainable partnership in quadruple helix entrepreneurial ecosystem.

In the following rows we will analyse the most important questions of the survey which will lead us to reach the aim of this study. One of the questions was if, in the region exist a need of innovation alliances to accelerate the economic development.

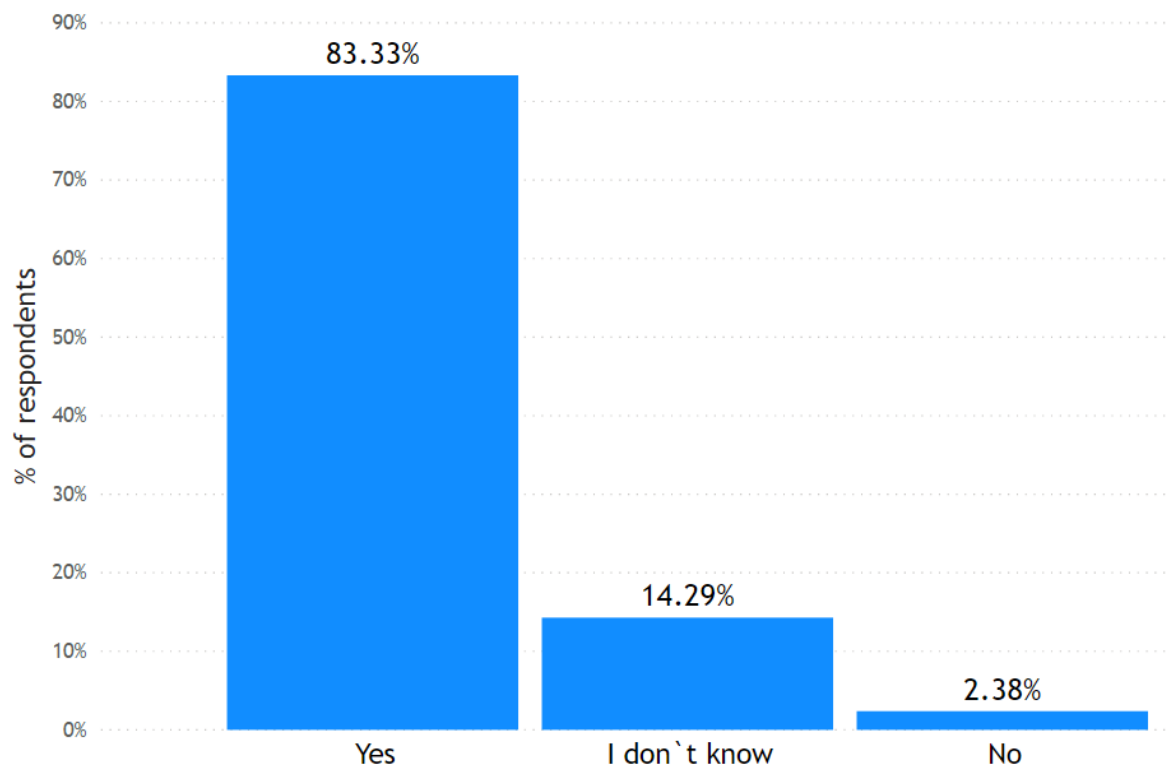

Figure 1. The need of innovation alliances in the context of quadruple helix entrepreneurial ecosystem

Source: Authors results and representation

As we see in the Figure 1 above, the majority of the respondents answered Yes and just 2.38\% answered No. In this case we can say that respondents agree about importance of existence of this kind of partnerships. In the following rows we will try to go deeper in analysis to 
discover what are preferences of stakeholders and if it's possible to act together.

Another important question of the survey was to identify the type of collaboration they want in relation with the university as a hub of innovation.
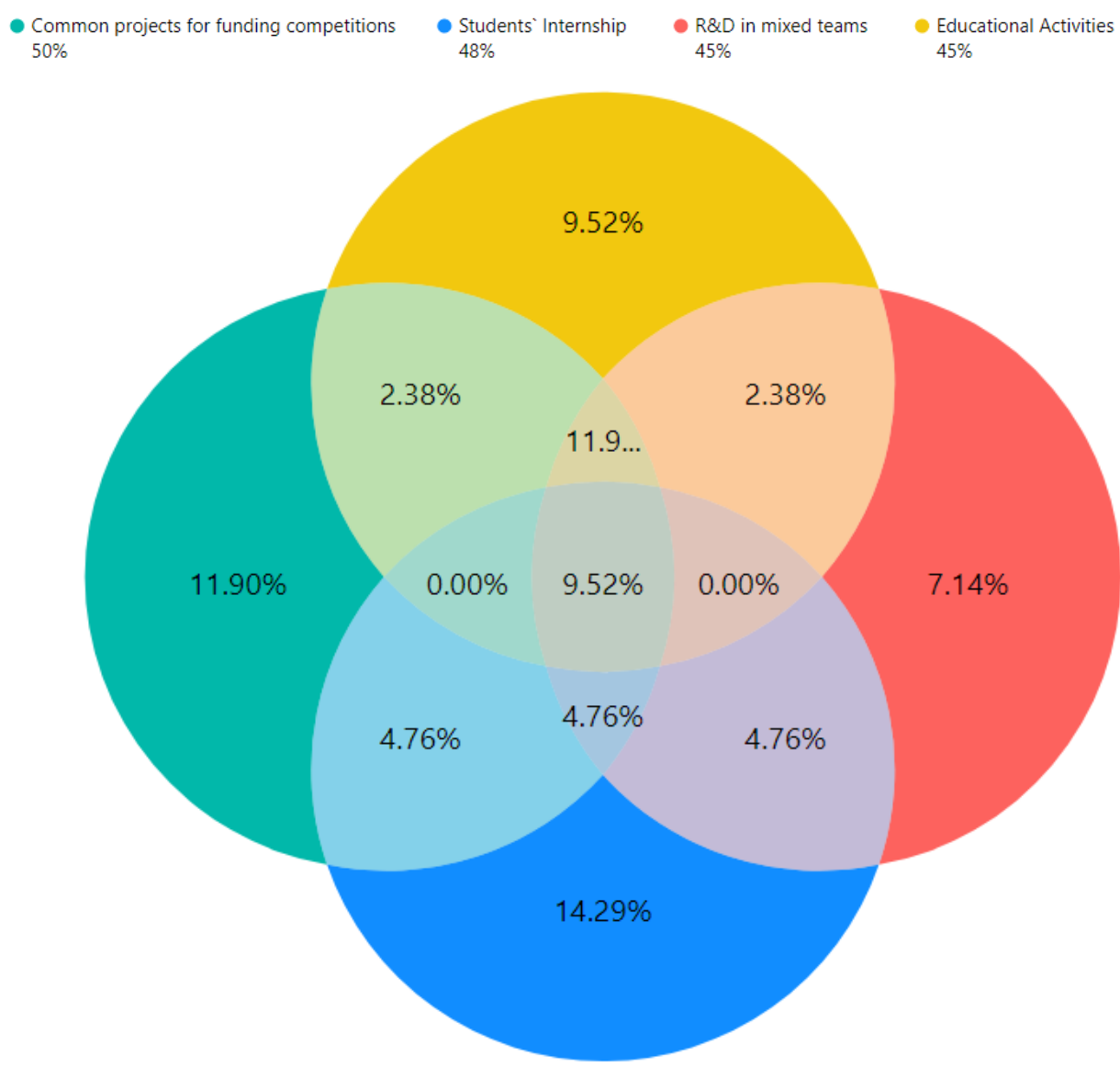

Figure 2. Types of collaboration preferred by the stakeholders

Source: Authors results and representation

As we notice above, the university playing important role in quadruple helix partnerships, especially when university is multidisciplinary one. The respondents were asked to choose the most important types of collaboration for them with university. In the figure $\mathrm{nr} 2$ we observe that 50 $\%$ of respondents are interested in common project with university for 
funding competitions. Also, what surprising us is the fact that $9.52 \%$ of respondents choose all top 4 types of collaboration.

In our nest next representation, we intend to show what are the most popular field of collaboration that can support the quadruple helix partnerships. From six fields of study where university have competences, most important one is Business and management, IT\&C, Sales, Tourism and other services and Law. Other two options which are not included in this list are Medicine field - where is clear methodology of collaboration and Science and Letters field - which is not the most popular in the region.

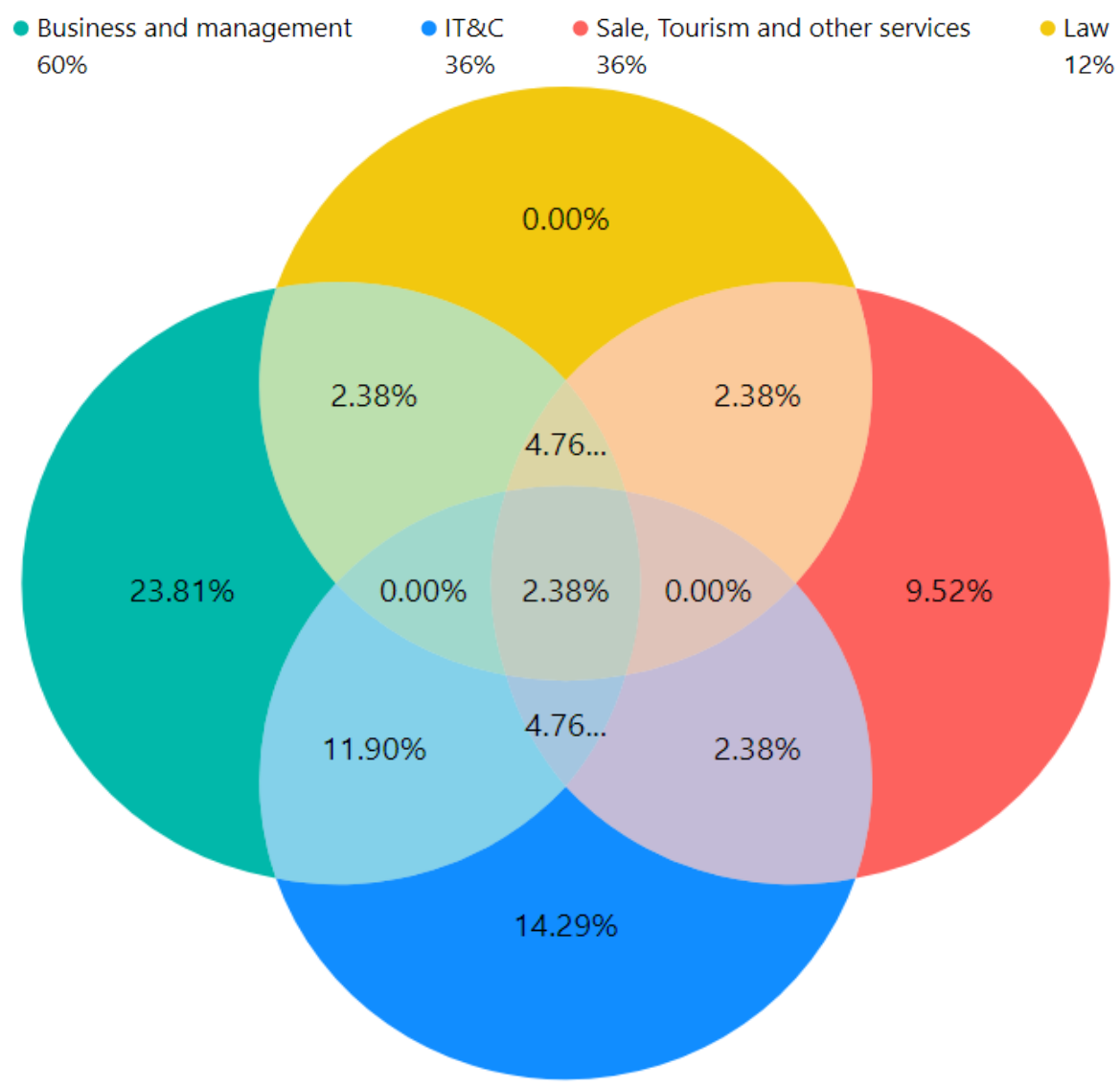

Figure 3. Top fields of intended collaboration

Source: Authors results and representation

In the figure 3 we can identify that $60 \%$ of respondents choose the Business and management field, also, as in previous figure, we see that 
$11.9 \%$ choose the combination from three or more fields. This mean that businesses`and public authorities `environment needs a multidisciplinary team to fulfill all departments inside organization with new skills and competences which can face all kind of tasks of the organization. Also, we identified preferences of respondents for IT\&C competences which are required in the digital era.

At the end of our analysis we must identify the intention of respondents to take a part of innovation alliances in the context of quadruple helix entrepreneurial ecosystem.

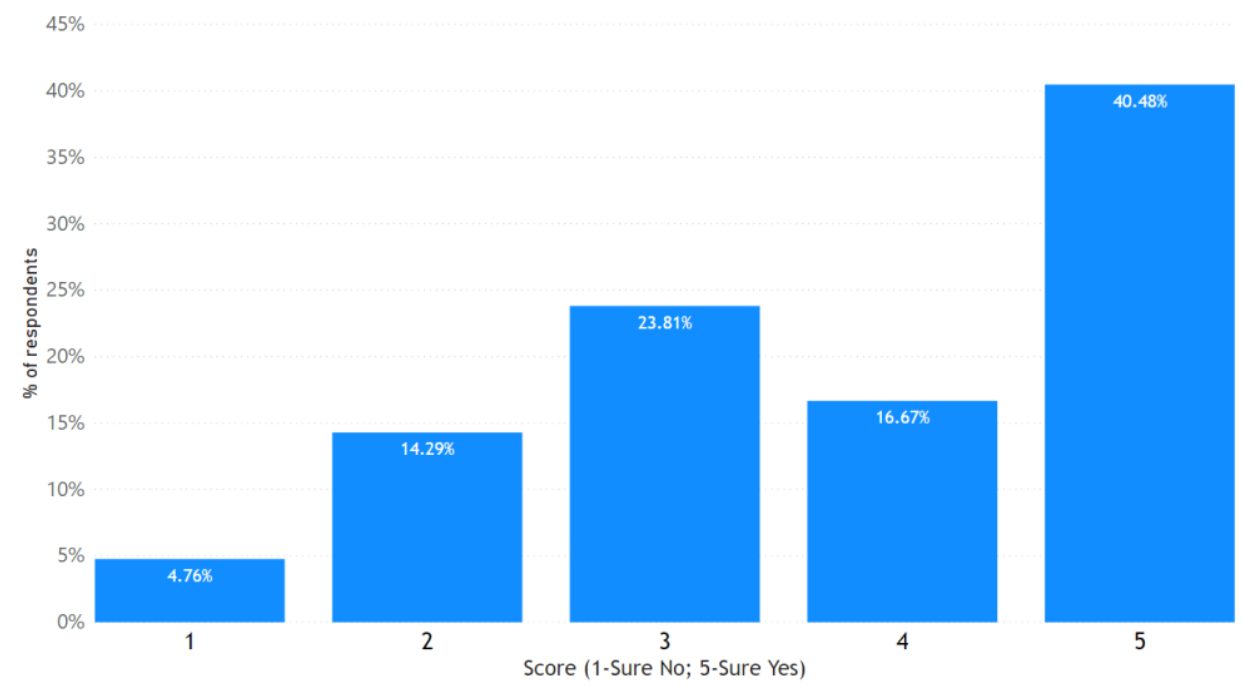

Figure 4. Respondents` intention to be involved in quadruple helix innovation alliances

Source: Authors results and representation

In the figure 4 , we can see that $40.48 \%$ of respondents are sure about taking part in innovation alliances. Also, we observed that $42.86 \%$ of the respondents are indifferent or not agree to be involved in this kind of activities. This mean that is no full openness from businesses and public authorities for collaboration in this form.

\section{Discussions}

This study was initiated in the context of promoting the innovation alliances where universities could play the key role as an initiator of the partnerships. Taking in account the previous experiences of the university in partnerships with public and private economic environment, development 
of new consortiums would not be a big challenge as the initiative and openness for collaboration from stakeholders.

In the following rows, we intend to show what is the structure of quadruple helix collaboration approach and the function of the actors involved.

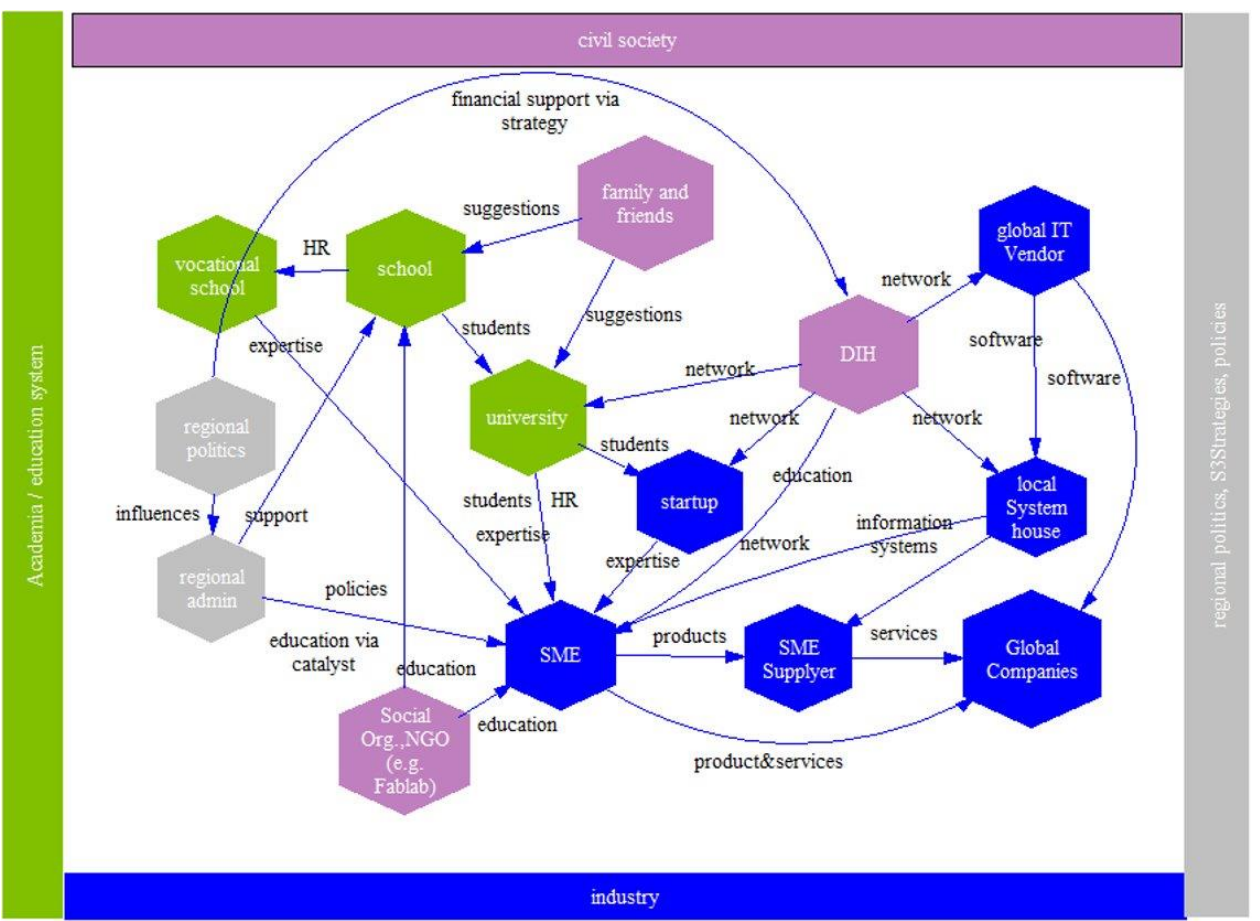

Figure 5. Model of a Digital Innovation Hubs-DIH

Source: Authors conceptualization

In figure 5 we see a model of quadruple helix elements and the way they interact with each other. We can observe how strong is the relation between actors involved and how important is entrepreneurial and knowledge exchange approach in this relationship.

A successful quadruple helix partnership takes into account all advantages of stakeholders even if this are financial, human resources, new knowledge and know-how, or other benefits of innovation alliances. In other words, sharing resources and developing together new opportunities are the key activities of innovation alliances context. 


\section{Conclusions}

The main findings of this research paper can suggest us the following conclusions and recommendations:

- The main topics of collaboration preferred by businesses and public authorities are related to the strategy of organization and lack of experience or human skills involved in process of implementation. At the same time, the fields of collaboration are more related to the expertise the organizations already have. Also, we observed the tendencies for multidisciplinarity approach regarding field of collaboration.

- Through quadruple helix stakeholders exist understanding of usefulness of innovation alliances and the importance of knowledge exchange from and to different fields. In other words, innovation comes from multidisciplinarity or do not come at all.

- This research paper crystallized the importance of alliances where through knowledge transfer and variety of competences and other resources available can be achieved high innovation performance. On other hand, the stakeholders do not express their full openness to collaborate in quadruple helix approach.

To promote the quadruple helix collaboration process, we need to ensure that we address to right actors and offer them enough reasons to invest time and resources in this king of partnerships. We are encouraged to state that nowadays the innovation is mostly about cooperation, interdisciplinarity, multi-sense knowledge exchange and agile approach. About the role of university, it must act as a hub of innovation to promote and support regional entrepreneurial ecosystem, to act as magnet of creative energies meant to shape a framework that can support the sustainable regional development.

\section{Acknoweldgement}

„This work was supported by a grant of the Ministry of Education and Research for higher education. "PLATINO project - Innovation Platform for sustainable development of pro-entrepreneurial behavior in the academic environment UMPhST G.E. Palade Targu Mures "CNFIS-FDI-2020-0177" 


\section{References}

[1] Carayannis EG, Grigoroudis E, Campbell DFJ, Meissner D, Stamati D. The ecosystem as helix: an exploratory theory-building study of regional co-opetitive entrepreneurial ecosystems as Quadruple/ Quintuple Helix Innovation Models. R D Manag. 2018;48(1):148-62.

[2] Cunningham JA, O'Reilly P. Macro, meso and micro perspectives of technology transfer. J Technol Transf. 2018;43(3):545-57

[3] Del Vecchio P, Elia G, Ndou V, Secundo G, Specchia F. Living lab as an approach to activate dynamic innovation ecosystems and networks: An empirical study. Int J Innov Technol Manag. 2017;14(5):1-18

[4] Franc A, Karadžija D. Quintuple helix approach: The case of the European Union. J Econ Bus Soc Issues. 2019;895(5):91-100.

[5] Tokman M, Mousa FT, Dickson P. The link between SMEs alliance portfolio diversity and top management's entrepreneurial and alliance orientations. Int Entrep Manag J. 2020;16(3):1001-22.

[6] Tseng FC, Huang MH, Chen DZ. Factors of university-industry collaboration affecting university innovation performance. J Technol Transf [nternet]. 2020;45(2):560-77. Available from: https://doi.org/10.1007/s10961-018-9656-6 